\title{
Riccardo Benedettini, I «Six livres de la Republique» di Jean Bodin tradotti da Lorenzo Conti. Tra segni di censura e filologia
}

\section{Dario Cecchetti}

\section{(2) OpenEdition \\ Journals}

\section{Edizione digitale}

URL: http://journals.openedition.org/studifrancesi/3698

DOI: 10.4000/studifrancesi.3698

ISSN: 2421-5856

\section{Editore}

Rosenberg \& Sellier

\section{Edizione cartacea}

Data di pubblicazione: 1 décembre 2012

Paginazione: 556

ISSN: 0039-2944

\section{Notizia bibliografica digitale}

Dario Cecchetti, «Riccardo Benedettini, I «Six livres de la Republique» di Jean Bodin tradotti da Lorenzo Conti. Tra segni di censura e filologia», Studi Francesi [Online], 168 (LVI | III) | 2012, online dal 30 novembre 2015, consultato il 06 mars 2021. URL: http://journals.openedition.org/studifrancesi/3698 ; DOI: https://doi.org/10.4000/studifrancesi.3698

Questo documento è stato generato automaticamente il 6 mars 2021.

\section{cc) $(9)$}

Studi Francesi è distribuita con Licenza Creative Commons Attribuzione - Non commerciale - Non opere derivate 4.0 Internazionale. 


\title{
Riccardo Benedettini, I «Six livres de la Republique» di Jean Bodin tradotti da Lorenzo Conti. Tra segni di censura e filologia
}

\author{
Dario Cecchetti
}

\section{NOTIZIA}

RICCARDO BENEDETTINI, I «Six livres de la Republique» di Jean Bodin tradotti da Lorenzo Conti. Tra segni di censura e filologia, in «Il Pensiero Politico», XLII-2 (2009), pp. 198-229.

1 La traduzione italiana dei Six livres de la Republique di Bodin ad opera del genovese Lorenzo Conti (1588), testimonianza di primo piano dell'immediata fortuna europea di una delle opere fondamentali della dottrina politica cinquecentesca, è una versione che si segnala per il costante grado di fedeltà all'originale. Sottoposta, tuttavia, al controllo inquisitoriale, ha subito interventi censori, senza contare alcuni interventi peraltro non di ordine dottrinale ad opera del traduttore stesso. L'A. studia, in questo saggio puntuale e interessante, tali interventi, seguendo appunto due direttive. Anzitutto evidenzia come «i tratti definitorî delle scelte siano legati principalmente a considerazioni soggettive, proprie del mondo ecclesiastico dell'epoca, come di 'coatta' cautela da parte del traduttore e dell'editore, che vogliono immettere il libro in una comunità attenta alla formazione dell'opinione pubblica». Gli interventi censori sono poi considerati in funzione di quella che l'A. definisce una filologia degli scarti. In questo campo «si colloca l'attenzione all'analisi stilistica, punto di vista sulle traduzioni dal francese all'italiano che permette di tirare gli assi di una prospettiva continua nella storia della cultura e della lingua del Cinquecento». 